\title{
Market access and regional dispersion of human capital accumulation in Turkey
}

\section{Author: Burhan Can Karahasan \& Firat Bilgel}

This is the peer reviewed version of the following article: [Market access and regional dispersion of human capital accumulation in Turkey. Review of Development Economics, which has been published in final form at https://doi.org/10.1111/rode.12676. This article may be used for noncommercial purposes in accordance with Wiley Terms and Conditions for Use of Self-Archived Versions: https://authorservices.wiley.com/author-resources/Journal-Authors/licensing/selfarchiving.html\#3.

Karahasan, Burhan Can, and Fırat Bilgel. "Market Access and Regional Dispersion of Human Capital Accumulation in Turkey." Review of Development Economics 24, no. 3 (May 27, 2020). doi:10.1111/rode.12676.

Made available through Montana State University's ScholarWorks

scholarworks.montana.edu 


\title{
Market Access and Regional Dispersion of Human Capital Accumulation in Turkey
}

\author{
Burhan Can Karahasan* Firat Bilgel ${ }^{\dagger}$
}

\begin{abstract}
Building on the early advances in development economics, the theoretical construct of the New Economic Geography asserts that geography plays a crucial role in educational human capital accumulation. Based on this expectation, this study investigates the impact market access on provincial human capital accumulation in Turkey. Results indicate that market access matters for understanding why some regions lag behind others in terms of average years of schooling. Our results are robust to the inclusion of spatial mechanisms, different specifications of the spatial weight matrix, endogeneity and alternative measurements of market access and to a host of other factors that affect regional human capital accumulation.
\end{abstract}

Keywords: human capital, market access, Turkey

JEL Classification: R11, R12

\footnotetext{
${ }^{*}$ Department of Economics and Finance, Piri Reis University, 34940 Istanbul Turkey. Email: bckarahasan@pirireis.edu.tr.

${ }^{\dagger}$ Department of Economics, MEF University, 34396 Istanbul Turkey. Email: bilgelf@mef.edu.tr.
} 


\section{Introduction}

Technological advances, productivity improvements and resource allocation efficiency have been central to economic theory (Solow, 1956; Lucas, 1988; Romer, 1994). Theoretical developments give momentum to applied work in understanding the mechanisms of exogenous and endogenous growth models. Majority of these empirical studies investigate the reasons and sources of between- and within-country differences (Barro and Sala-i Martin, 1995; Sala-i Martin, 1994; Howitt, 2000). However, distribution of the factors that explain economic growth differences across and within countries is also a vital research area for development economics. Among various dimensions, human capital development has been central to growth and development economics (Benhabib and Spiegel, 1994). Specifically, educational human capital accumulation facilitates various lines of economic growth such as earnings and productivity enhancements, social and economy wide developments, division and coordination of labor, among the others (Becker, 1964).

Educational human capital accumulation is a crucial element for economic prosperity. Therefore, reasons behind its distribution across and within countries become a vital line of research for development economics. One common way of approaching to human capital based differences stems from incentives, returns of education and the positive effect of educational policies (Psacharopoulos, 1988). A growing body of work questions the endogenous link between human capital accumulation and economic development by emphasizing the importance of geographical linkages and market-based incentives in order to stimulate human capital development. These recent discussions originate from the role of agglomeration economies in understanding differences in the level of economic activity (Krugman, 1991). Indeed, Gallup et al. (1999); Henderson et al. (2001) suggest that geography is important not only because increasing returns matter but also many economic and social dimensions of inequalities have a geographic dimension. While neo-classic theories consider the importance devoted to geography by specifying first nature advantage, New Economic Geography (NEG) literature discusses the role of agglomeration economies in understanding the local differences in the level of economic activity (Krugman, 1991). Developments in the NEG reached a milestone upon the use of market accessibility concept for explaining per capita income disparities across countries. (Redding and Venables, 2004a,b). Note that, NEG framework initially concentrates on economic and monetary inequalities. Increasing returns, existence of externalities and the spillover of knowledge are essential elements, which are used by the NEG approach to explain the geographical differences in the level of economic activity. The success of this framework in explaining the ongoing regional disparities encourage further studies to understand the impact of geography on the sources of economic growth inequalities.

The formulation of NEG originates from agglomeration economies and possible externalities of market accessibility. While these domains influence economic well-being, different channels can be effective in order 
to understand the relationship between the determinants of economic growth and agglomeration economies. Revisiting productivity and technology differences, the NEG literature explains the pattern of regional integration and factor accumulation by using their own formal models. Coe and Helpman (1995); Coe et al. (1995); Keller (2000) discuss the negative impact of distance on technological spillovers, however it is Redding and Schott (2003) to discuss the endogenous evolution of production factors (i.e. human capital) within an augmented NEG model.

While distance is a negative factor for the integration and spillover of economic activity, other dimensions such as trade, income and economic potential are mostly neglected. The NEG framework enables the embedding of different economic indicators into an accessibility measure. In this new formulation, distance acts as a compound factor (i.e. iceberg transportation costs) that influences the impact of different economic variables. This market accessibility and potential (market access hereafter) forms the backbone of agglomeration economies and externalities within the NEG models. Specifically, two strands of literature use market access. While some studies directly focus on the impact of market access on the level of economic activity (Hanson, 2005; Head and Mayer, 2006), another line examines the relationship between market access and the endogenous accumulation of production factors (Redding and Schott, 2003). The former specification is interested in the dispersion of wages, productivity differences and economic activity variation whereas the latter tends to understand how production factors (i.e. human capital) vary based on the distribution of market accessibility.

Originating from the development aspects of geographical disparities, this research relies on the second line of literature and questions the extent of the link between market access and human capital development. Based on the NEG framework, geographically central firms and regions that escape the curse of distance earn more profits and generate extra value-added to production factors (i.e. skilled premium to educated workers). Therefore, expecting higher wage premiums in central locations is a stimulus for individuals to invest more in human capital development. A growing body of empirical work suggests that regions that have higher market access are also the ones with more human capital accumulation. (Redding and Schott, 2003; Faína and López-Rodríguez, 2006; López-Rodríguez et al., 2007; Diebolt and Hippe, 2018; López-Rodríguez et al., 2019).

The NEG model receives considerable attention for developed countries; however, little is known about the relationship between market access and human capital in developing and less developed countries. In a recent discussion, Amaral et al. (2010) assesses a developing country case, Brazil, by only focusing on regional disparities measured by wages. López-Rodríguez et al. (2011) validates the positive impact of spatiality and geographical accessbility on wage distribution for Romania. Similarly, López-Rodríguez et al. (2014); López-Rodríguez (2015) explores the Polish case by suggesting that market accessbility is an important 
part of regional disparities in a developing country example. Similarly, Karahasan et al. (2016) highlights that market access explains the spatial distribution of wage disparities across the Turkish regions. While geographical proximity and market access are linked with regional disparities, , evidence is lacking for developing countries once the impact of market access on production factor (i.e. human capital) dispersion is considered. One exception is López-Rodríguez et al. (2019) who suggest that market access influences human capital distribution across the Romanian regions. From a different perspective, Alvarado et al. (2014) argue that the influence of market access on regional disparities in Ecuador can be influenced from human capital-based differences; however this relationship among these domains (market access, human capital development, regional disparities) can be affected by the nation-wide development level of the countries. Therefore, the central objective of this research is to investigate the link between market access and human capital development for a developing country, Turkey, suffering from a substantial level of regional disparities. While one strand of the Turkish literature focuses on the socio-economic development of different segments of the society through gender, ethnicity and age decomposition, another line of research explores the regional dimension (Doğruel and Doğruel, 2003). In this study, we investigate the NUTS III (Nomenclature of Units for Territorial Statistics - III) level regions (81 provinces) of Turkey for the 2008-2017 period. In order to understand how the socio-economic change in Turkey influences regional development patterns, we test the NEG model by comparing the regional evolution of market access and average years of schooling. While doing this, we take into account spatial externalities, endogeneity of market access, regional heterogeneities and other factors that are likely to influence regional human capital development differences.

This study contributes to the existing literature through empirical and methodological perspectives. Moreover, we argue that our findings give more room for development economics to discuss the peculiar nature of geographical proximity especially in developing and less developed countries. From an empirical perspective, focusing on the reasons behind regional differences in human capital accumulation stands as a valuable contribution. Even though empirical studies use human capital as an important element for regional and cross-country differences, the number of applications to examine the reasons behind the evolution of human capital gaps is limited. Similarly, as much as a rich body of literature examines how market access can affect regional variation of economic activity within the NEG's formulation, the reasons behind the accumulation of human capital are relatively less investigated. Regardless of the preferred approach (interest on economic activity or human capital) the majority of evidence for the NEG comes from developed countries.

Based on the under-investigation of developing countries within the NEG literature, examining Turkey as a developing country case is an additional empirical contribution. We consider Turkey to be important and peculiar based on two important characteristics of the Turkish economy: (i) Persistent regional duality 
between underdeveloped east and developed west, (ii) Continuous transformation and change in institutional, economic and social environment of Turkish economy during the last two decades.

Regional disparities in Turkey is a remarkable part of development concerns. Although different policy measures are considered to combat disparities, results are mostly unsuccessful in closing the gap between eastern and western parts of the country. Therefore, there is a great need to understand the impact of agglomeration economies on economic activity and factor distribution in Turkey. Although different dimensions of inequalities have been considered in Turkey (Filiztekin, 1998; Doğruel and Doğruel, 2003; Gezici and Hewings, 2007), attempts to implement the NEG framework are relatively scarce. There is no discussion on how agglomeration may alter human capital-based factor dispersion, notwithstanding the link between market access and wages has been tested for the 1980-2000 period (Karahasan et al., 2016). However, our existing knowledge on human capital-based disparities confirm that Turkey is one of the significant examples, among developing countries, that suffers from clear human capital-based disparities (Erdem, 2016).

An additional dimension of our study is related to the period analyzed, which corresponds to a significant transformation of economic and social institutions in Turkey. As Cizre and Yeldan (2005); Lagendijk et al. (2009) argue, post-2000s represent rapid adjustment and change in various grounds. Economic institutions that influence macro-policies and social setups, which can affect poverty and inequality-motivated policies, are in a flux during the post-2000s in Turkey. Evidence also suggest that regional disparities are extremely persistent and stand historically, a long-run policy choice for Turkish economy (Doğruel, 2006). Therefore, market-driven aspects of educational disparities are important aspects of our study in order to understand how market accessbility affects regional human capital gaps during a period of rapid change and transformation in a developing country. To the best of our knowledge, no attempt has been made in order to understand various dimensions of agglomeration and market accessibility for the post-2000s in Turkey.

Methodologically, we aim at contributing to other studies testing the NEG framework by carrying out a number of exercises to test the robustness of the empirical results of the NEG model. First, we control for the impact of spatial externalities, which has not been central to the NEG model. Albeit there are attempts to include a battery of spatial models into the NEG model (Karahasan and López-Bazo, 2013), discussions on the direct and the indirect influences of spatial mechanisms on the true link between market access and human capital accumulation are missing. We treat spatial channels not only as basic controls in our econometric specifications but also foresee that the inclusion of spatial mechanisms may alter other sub-channels that are likely to influence the link between market access and human capital accumulation. This enables us to discuss the policy dimension regarding accessibility and the impact on the incentives to invest in human capital accumulation. 
A related dimension of the methodological contributions lies in the investigation of the mechanisms between human capital accumulation and regional evolution of market accessbility. Potentially, identifying how individuals decide education investment is central to the proposed theoretical setup. One vital threat to our identification strategy is the endogeneity of market access. Moreover, other dimensions and mechanisms related with the labor markets of regions (i.e. skill sorting and attractiveness of city centers) are not directly central to the theoretical model. Failing to consider these problems may result in inconsistent estimates of the effects of market access on human capital accumulation (Combes et al., 2008; Redding, 2010). As labor market policies and regional development are both central for spatial cohesion, especially in developing countries like Turkey, more effort is required to understand the background behind human capital disparities. Even though no consistent regional wage and occupation data is available at regional level for the analysis period, we control for the possible endogenous relations between educational human capital and accessibility of Turkish regions. Our robustness exercises provide evidence on the validity of the NEG framework for a developing country and help shape the extent and efficiency of regional policies to combat human capitalbased inequalities.

Section 2 overviews the theoretical background, section 3 introduces the empirical strategy, section 4 reports the results, section 5 discusses the policy implications derived from the comparison of two different approaches and section 6 concludes.

\section{Theoretical Background}

Krugman (1991), Krugman and Venables (1995), Venables (1996) and Fujita et al. (1999) formalized the way agglomeration economies explain the distribution of economic activities by highlighting the importance attributed to distance and market accessibility. Being close to markets represent the market accessibility of locations. Naturally, locations with higher market access benefit from externalities generated among their geography.

Redding and Venables (2004a,b) use this NEG reasoning and define market access/potential in order to explain inequalities across nations. Accessibility is defined in two different forms: (i) market access (MA) referring to being close to demand, (ii) supply access (SA) defines how firms may access to sources of production. While the theoretical model distinguishes supply and market access; given the high correlation between the two, empirical specifications tend to focus only on market accessibility.

Redding and Venables (2004b); Breinlich (2006); Boulhol and De Serres (2010); Hering and Poncet (2010); Head and Mayer (2011) compute MA based on a gravity equation; Bosker and Garretsen (2010) use distance as a weight for regional demand potential (i.e. income, value added, population) and Mion (2004); Hanson 
(2005); Ottaviano and Pinelli (2006); Niebuhr (2006); Brakman et al. (2006); López-Rodríguez et al. (2007); Kosfeld and Eckey (2010) López-Rodríguez et al. (2011, 2014, 2019). compute the distance-weighted version of market accessibility. Regardless of the method used, studies show that firms, regions and countries that have better access to markets tend to be wealthier on average.

Redding and Schott (2003) offers a wider perspective that does not only explain the distribution of income but also the endogenous accumulation of production factors. Firms in remote locations face higher trade costs, which prevent them to accumulate more sources to be distributed to production factors. In contrast, firms that have higher market access generate higher profit and are more likely to compensate for the production factors. Among different factors, human capital and specifically skilled human capital tends to benefit more as firms become more reluctant to pay the required skill premium in central locations. Redding and Schott (2003) defines this condition by introducing the following wage equation:

$$
\left(\frac{\sigma}{\sigma-1}\left(w_{i}^{s}\right)^{\alpha}\left(w_{i}^{u}\right)^{\beta} G_{i}^{(1-\alpha-\beta)} c_{i}\right)^{\alpha}=\left(\frac{1}{\bar{x}}\right) \sum_{j=1}^{R} E_{j} G_{j}^{\sigma-1}\left(T_{i j}^{M}\right)^{1-\sigma}
$$

where $w_{i}^{s}$ and $w_{i}^{u}$ represents wages to skilled and unskilled workers with $\alpha$ and $\beta$ factor shares respectively, $\sigma$ is the elasticity of substitution, $E$ is the consumption of manufacturing goods with a price index of $G$, $c$ denotes marginal input requirement and $T_{i, j}^{M}$ is an iceberg-type transportation cost for manufacturing production $(M)$. Re-arranging equation (1) yields:

$$
\left(w_{i}^{s}\right)^{\alpha}\left(w_{i}^{u}\right)^{\beta}=\zeta \frac{1}{c_{i}}\left(M A_{i}\right)^{\frac{1}{\sigma}}\left(S A_{i}\right)^{\frac{(1-\alpha-\beta)}{(\sigma-1)}}
$$

which defines the maximum amount a firm in region $i$ can afford to pay to its skilled and unskilled workers, where $\zeta$ is a constant containing the impact of manufacturing intermediary goods.

The skilled indifference condition that shows how individuals decide human capital investment is given by:

$$
w_{i}^{s}-w_{i}^{u} \geq \frac{h_{i}}{a(z)} w_{i}^{u}
$$

where $w_{i}^{s}-w_{i}^{u}$ is the skilled premium, $a(z)$ is the critical ability level and $h_{i}$ is an institutional parameter assumed to be homogenous for regions of the same country such that the right-hand side represents the cost of education.

$$
\alpha \frac{d w_{i}^{s}}{w_{i}^{s}}+\beta \frac{d w_{i}^{u}}{w_{i}^{u}}=\frac{1}{\sigma} \frac{d M A_{i}}{M A_{i}}+\frac{(1-\alpha-\beta)}{(\sigma-1)} \frac{d S A_{i}}{S A_{i}}
$$


Equation (4) implies that a fall in market access defines a lower relative wage rate for skilled workers if manufacturing production is skill-intensive. In the new equilibrium condition, a higher critical ability level is defined over which individual becomes a skilled worker (Faíña and López-Rodríguez, 2006; López-Rodríguez et al., 2007). This results in less incentive to accumulate human capital if regions are faced with diminishing market accessibility.

Overall, the NEG model defines that the relationship between market access and wages (equation (2)) affects the individuals' human capital accumulation decision (equation (3)). That is, the impact of geography on human capital accumulation works through a channel in which a positive relationship between market access and human capital accumulation is defined. The NEG model assumes that individuals' education decisions are nudged by the expected future skilled premium. As skill premium is a positive function of market access; we expect a positive relationship between market access and human capital accumulation.

Empirical studies widely use the Redding and Schott (2003) model, however, the NEG model should be overhauled for problems such as misidentification and missing mechanisms (Redding, 2010). For instance, the link between market accessibility and factor accumulation of human capital is affected by the spatial dimension of inequalities and structural differences in production (Karahasan and López-Bazo, 2013). Moreover, the theoretical background of the NEG model lacks a formal explanation on how wages and human capital are connected. Other factors that affect wages might also have a geographical pattern (Motellón et al., 2011). More importantly, the endogeneity of MA is an important dimension of the existing NEG model (Boulhol and De Serres, 2010; Karahasan and López-Bazo, 2013; López-Rodríguez et al., 2019).

In the following section, we discuss various dimensions of regional evolution of market access and human capital development by controlling for structural differences, regional heterogeneities, spatial spillovers and the endogeneity of market access.

\section{Empirical Strategy}

\subsection{Data and Sample}

We use province-level (Nomenclature of Units for Territorial Statistics III - NUTS III) balanced panel data, covering 81 provinces of Turkey for the period of 2008-2017. ${ }^{1}$ In order to control for regional human capital differences, we calculate the average years of schooling at the NUTS III level whose raw data is retrieved from Turkstat (2019). We lack historical data for the pre-2008 period for human capital accumulation although it would be possible to obtain regional data from population censuses conducted in 1985 and 2000 .

\footnotetext{
${ }^{1}$ All data used in this study are available from Turkstat (2019) and www.tuik.gov.tr.
} 
However, it would be incompatible with the current panel dataset due to lack of information for the missing years between censuses and the 2008-2017 panel data. Besides, the number of regions varies between 67 to 81 before 2000 due to changes in the administrative boundaries of certain Turkish regions. Under these circumstances, focusing on two cross-sections only for the pre-2000s would have a limited contribution due to a failure to control for time-invariant cross-sectional heterogeneity. Still, we have conducted cross-sectional analyses for the previous cross sections (1985 and 2000) and end up with similar results. These results are available upon request.

Following Harris (1954), market access index is given by:

$$
M A_{i}=\sum_{j=1}^{n} \frac{Y_{j}}{D_{i, j}}
$$

where $Y_{i}$ is the per capita income of region $i$ (Turkstat, 2019) and $D_{i, j}$ is the motorway distance between any pair of regions $i, j$, retrieved from the General Directorate of Highways Republic of Turkey. ${ }^{2}$ Since, regional GDP is in nominal terms, we use regional Consumer Price Index (CPI, 2003=100) to deflate regional market access values. Regional CPI data retrieved from Turkstat (2019) is only available at the NUTS II level. We distribute regional CPI values from NUTS II to NUTS III level accordingly. ${ }^{3}$

Redding and Schott (2003); Redding and Venables (2004a) use the gravity approach to calculate market access. This complex two-step approach is criticized on the grounds that one has to make a set of arbitrary assumptions on the structure of trade costs. Region-specific properties like distance, adjacency, trade barriers, language etc. can overestimate the regional properties resulting in biased measurement of market accessibility (Anderson and Van Wincoop, 2004; Fingleton, 2008; Bosker and Garretsen, 2010). Based on these concerns and the lack of reliable data to implement the gravity approach for Turkey, we use distance-weighted per capita income approach rather than an auxiliary gravity model in our market access calculations. Following Karahasan and López-Bazo (2013); López-Rodríguez et al. (2019) we consider within region dynamics by calculating the internal demand, weighted by the intra-regional distance via Head and Mayer (2006) approximation of $D_{i, j}=0.66 \sqrt{\text { Area }_{i} / \pi} \cdot{ }^{4}$

While our empirical strategy allows us to control for all time-invariant factors that may affect human capital accumulation, we further add time-varying regional controls. These include employment share in

\footnotetext{
${ }^{2}$ Other ways to measure distance include travel time distance and bird-eye distance. Bird-eye distance fails to control for topographical differences of Turkish geography and may underestimate the impact of true distance, especially for the mountainous eastern regions. For the travel time distance, we lack reliable historical data. Therefore, throughout the paper, market access is calculated using the road distance. In order to check for the robustness of our results we also provide results from a MA index derived using bird-eye distance.

${ }^{3}$ We also consider national CPI and GDP deflator in order to calculate the real market access. The results using either measure remain virtually unchanged and are available upon request.

${ }^{4}$ Direct distance to certain locations can also be used in order to understand the ease of market access (Faína and LópezRodríguez, 2006; López-Rodríguez et al., 2007). We take into account the direct distance to Istanbul, Ankara and Izmir, which are important economic centers in Turkey.
} 
service and agriculture to understand the regional variation in production structure and labor demand, net migration rate and unemployment rates. Employment data, provided by Turkstat (2019), is available at the NUTS II level. Net migration rate is available at the NUTS III level, and the unemployment rate is available at NUTS III for the 2008-2013 and at the NUTS II level for the 2013-2017 period. Both migration and unemployment rates are available from Turkstat (2019). The first three columns in Table 1 report the mean, the minimum and the maximum values of the variables employed in the analysis for the 2008-2017 period along with standard deviations.

\subsection{Exploratory Spatial Data Analysis}

In order to account for spatial auto-correlation we invoke the global Moran's I statistic:

$$
I=\frac{n}{s} \frac{\sum_{i} w_{i j}\left(x_{i}-\bar{x}\right)\left(x_{j}-\bar{x}\right)}{\sum\left(x_{i}-\bar{x}\right)^{2}}
$$

where $n$ is the number of cross-sections, $s$ is the summation of all the elements $w_{i j}$ of the weight matrix W of provinces $i$ and $j$ (Anselin, 1996). The global Moran's I shows the extent of spatial autocorrelation. It ranges between -1 and +1 , where -1 indicates perfect spatial randomness (i.e. checkerboard pattern) and +1 indicates perfect spatial clustering. We consider three commonly used spatial weight matrices to compute the Moran's I: a row-normalized first-order queen contiguity matrix whose elements are one if two provinces have a common border and zero otherwise, a spectral inverse distance spatial weight matrix where the elements $w_{i j}$ of the matrix $\mathbf{W}$ contain the inverse of the distance between the centroid of provinces $i$ and $j$, and is divided by its largest characteristic root (i.e. spectral normalization) and a $k$-nearest neighbor weight matrix, where a threshold distance is determined based on the rule that each region has at least $k$ number of neighbors. The elements of a k-nearest neighbor weight matrix are one if the actual distance between two regions is smaller than the threshold distance and zero otherwise. We use four regions for determining the threshold cut-off distance. While there is no given rule for the exact number of regions, we replicate spatial analyses with alternative neighbor numbers. These results are also available upon request.

While the global Moran's I shows the extent of spatial externalities, it fails in identifying the source of spatial dependence. Therefore, following Anselin (1995) a decomposition analyses is carried out and the

global Moran's I is decomposed into a local measure. The Local Indicator of Spatial Association (LISA) is given as:

$$
I_{i}=\left(x_{i}-\bar{x}\right) \sum_{j} w_{i j}\left(x_{j}-\bar{x}\right)
$$


LISA analyses decompose the global measure into four significant spatial regimes; High-high (H-H), Low-Low (L-L), High-Low (H-L), Low-High (L-H). Regions within H-H and L-L clusters are composed of spatially connected regions with above and below average values, respectively. On the contrary, H-L and L-H are spatial outliers that represent deviations from the spatial proximity. ${ }^{5}$

\subsection{Patterns of Spatial Dependence}

An important but missing dimension of the original Redding and Schott (2003) is the lack of a discussion on cross-sectional spillovers. Likewise, empirical studies testing the market access and human capital accumulation link mostly neglects the inter-regional spillovers. While Karahasan and López-Bazo (2013) highlights the significant influence of spatial networks for the case of Spain, a similar analysis for a developing case study has not been conducted before. Therefore, we construct an augmented NEG model of the Redding and Schott (2003) by embedding spatial dependence and estimate a generalized panel spatial fixed-effects model for the 2008-2017 period that can be compactly written as:

$$
E_{t}=\mu_{i}+\beta M A_{t}+\rho W E_{t}+\gamma X_{t}+W X_{t} \theta+u_{t}
$$

$$
\text { and } \quad u_{t}=\lambda W u_{t}+\epsilon_{t}
$$

where $E_{t}$ is a $n \times 1$ column vector of average years of schooling for each period $t, t=1, \ldots, T$; MA is the natural $\log$ of market access; $X_{t}$ is a $n \times 4$ matrix that consists of the share of industry and services in GDP, unemployment share and net migration rate, $\mu_{i}$ is the province fixed-effect, $\mathbf{W}$ is a $n \times n$ spatial weight matrix with elements $w_{i j}$ indicating the relative connectivity between province $i$ and $j$, and $\rho, \theta$ and $\lambda$ indicate the average strength of these effects conditional on $\mathbf{W}$. In our benchmark analyses the weight matrix $\mathbf{W}$ is specified as a spectral inverse distance matrix. In Sub-section 4.3 we test the robustness of our results by using other types of weight matrices (i.e. contiguity, k-nearest neighbor).

Following Anselin (2010) and Elhorst (2010) we use four different spatial specifications. When $\rho=\theta=0$, we obtain the spatial error model (SEM) that considers common spillover of shocks thus omitted variables. When $\theta=\lambda=0$, we obtain the spatial lag model (SAR) and the spillovers or externalities arise from the outcome. When $\lambda=0$, we obtain the spatial Durbin model (SDM), allowing for global spillovers in observables. Finally, when $\rho=0$, we obtain the spatial Durbin error model (SDEM) that allows for local spillovers in observables. We follow the approach offered in Elhorst (2010) to compare the spatial models'

\footnotetext{
${ }^{5}$ Our LISA analyses employ an inverse distance weight matrix and are replicated using a queen contiguity and a k-nearest neighbor weight matrix. These results are available upon request.
} 
specifications.

One should take into account the fact that geography enters into these models in two different forms; over the MA variable and the weight matrix $(\mathbf{W})$. Naturally, overrepresentation of the geographical dimension is possible. However, the weight matrix is incorporated to define location-based networks over spatial dependence. On the contrary, market access variable incorporates the impact of purchasing power, weighted by the distance.

Finally, we take into account the possible endogeneity of market access. This has not been discussed in details within the NEG model, however omitted variables that are likely to explain human capital variable and the possible reverse causality running from human capital development towards market access are the two crucial aspects that have to be considered. To deal with the endogeneity issue, we construct a number of instrumental variables (IV) models, where we use spatial lags and variants of sum of distances as instruments for market access. Accounting for endogeneity is a sound exercise to deal with unobserved factors and reverse causation; however, it would still not be possible to examine the underlying sub-channels and the mechanics of the theoretical model. While, it is not our central aim to examine the background of the NEG's formulation, we acknowledge this limitation and discuss potential gateways for this in Section 5 .

\section{Findings}

\subsection{Descriptive Findings}

We first examine the regional distribution of human capital development and market accessibility in Turkey. Figure 1 plots the spatial distribution of average years of schooling. Regions that are clustered in the northwestern and western Turkey together with a set of regions in the south and in the center form the group of regions with the highest average years of schooling. On the contrary, the schooling levels are very low for the eastern and specifically south-eastern regions. Moreover, the regional distribution of average years of schooling is highly persistent. Highly educated regions in 2017 are mostly the ones that were already highly educated in 2008. These findings are in line with the prior literature on human capital-based inequalities in Turkey (Filiztekin and Karahasan, 2015; Erdem, 2016).

In order to examine accessibility, we calculate the market access index as in Harris (1954). The spatial distribution of Turkish regions' market access is illustrated in Figure 2. The pattern shows duality of market accessibility. High MA areas are significantly agglomerated in the western Turkey. On the contrary, eastern regions suffer from low levels of MA.

An important dimension of average years of schooling and market access is the visible spatial pattern. 
That is, both average years of schooling as well as market access show a significant amount of spatial clustering. In order to understand the extent of regional spillovers, spatial auto-correlations are reported in the last six columns of Table 1. Two important findings are worth underlining. First, market access displays stronger spatial dependence compared to average years of schooling, suggesting that spatial externalities created by agglomeration economies transcend education-based human capital spillovers. Second, our results show that for both variables, spatial dependence is stronger and closer in size upon the use of contiguity and k-nearest neighbor weight matrices compared to inverse distance. This suggests of the locality of spatial dependence. ${ }^{6}$ The global Moran's I statistic shows that the null hypothesis of spatial randomness can be rejected at the 1 percent significance level in favor of spatial clustering for all control variables employed.

While the global measure of spatial auto-correlation is useful in order to understand spatial spillovers, local decomposition analysis is essential. Therefore, we carry out the LISA analyses and decompose the early findings on spatial auto-correlation. ${ }^{7}$ Table 2 gives the summary of the results for the entire sample period. The first important result is the high share of regions reported in $\mathrm{H}-\mathrm{H}$ and L-L spatial regimes for both the average years of schooling and market accessibility. Note that outliers do not have a uniform pattern. However, the rise in the H-L outliers for average years of schooling signals the transition of some less developed and educated regions towards higher education levels. Overall, the decomposition of spatial patterns together with our early remarks on spatial distribution of average years of schooling (Figure 1) and market access (Figure 2) show the existence of parallel patterns between market accessibility and regional human capital accumulation.

A preliminary comparison of regional dispersion of human capital development and market access is indicative of similarities. This similarity becomes more pronounced in Figures 3 and 4 . There is a clear positive relationship between average years of schooling and accessing to markets. Additionally, following López-Rodríguez et al. (2007); López-Rodríguez et al. (2019) we also consider direct distance to specific economic centers of Turkey: Istanbul, Izmir and Ankara. These regions are historically the dominant economic activity areas of Turkey (Karahasan et al., 2016). Results indicate a negative relationship between distance to specific economic activity areas and average years of schooling, supporting the view that distance to economic centers and accessing to markets are both crucial elements for higher human capital development.

\subsection{Empirical Results}

The results of the baseline panel spatial fixed-effects models are given in Table 3. Our baseline models use motorway distance to calculate MA. The first four columns in Table 3 report the results without any control

\footnotetext{
${ }^{6}$ See Monastiriotis (2009) for details.

${ }^{7}$ As highlighted before, at this stage we only report the results from the inverse distance weight matrix. Results from the two other weight matrices are available from the authors upon request.
} 
variables. Columns (X.1) and (X.2) reports the results with an endogenous interaction effect (i.e. SAR) and a residual interaction effect (i.e. SEM) respectively. Columns (X.3) and (X.4) respectively reports the results for a residual interaction with a spillover effect of the independent variable (i.e. SDEM) and an endogenous interaction effect with a spillover of the independent variable (i.e. SDM). Note that for the baseline analyses, all spatial models are estimated by using a spectaral inverse distance weight matrix.

Without using any control variables, the LM diagnostics for spatial dependence at the bottom of Table 3 suggest the need to employ a spatial model. Specifically, while both the LM error and LM lag tests are significant, their robust versions indicate that a spatial error model is more appropriate. Further, the linear hypothesis testing for the spatial lag $(\rho=0)$ and the spatial error $(\lambda=0)$ terms suggest that they are individually statistically and significantly distinguishable from zero at conventional test levels.

However, the restriction on the spatial lag parameter for the MA variable in column (1.3) of Table 3 indicates that the effects of the spillovers in MA are distinguishable from zero. While the LR test (SEM vs. MODEL) in column (1.3) suggests that the SDEM cannot be constrained to the SEM at 1 percent significance level, the LR test in column (1.4) suggests that the SDM can be constrained to the SEM. The LR test (SAR vs. MODEL) in column (1.4) suggests that the SDM cannot be constrained to the SAR either. Under the battery of these diagnostic tests for model selection, the SDEM and potentially the SDM are more likely to best describe our data.

In the last four columns of Table 3, we augment our baseline models by additionally controlling for a host of factors that are likely to explain the variation in human capital. Notice that the implications of model selection criteria remain virtually the same, that the SDEM and the SDM best describe our data. Further, these models are also characterized by the highest log-likelihood and by the lowest Akaike Information Criterion in columns $(2 . \mathrm{X})$.

The partial derivative interpretation of the impact of market access on human capital constitutes a more valid basis for inference than focusing on the parameter estimates (LeSage and Pace, 2009). We therefore report the direct spatial effects by the average of the diagonal elements and the indirect spatial effects by the average of row or column sums of the off-diagonal elements of the matrix of partial derivatives.

The consistency of the significance of the parameter estimates across model specifications, either in terms of the patterns of spatial dependence or in terms of covariate inclusion, are staggering. However, the magnitude of the direct spatial effects of MA across the four spatial models we considered varies drastically, with the smallest effects under the SAR and the largest effects under the SEM. Nevertheless, the direct, indirect and the total spatial effects do carry the expected sign and are statistically distinguishable from zero at the 1 percent significant level, indicating that higher market access is associated with greater human capital accumulation. Moreover, this relationship is robust to the inclusion of additional control variables. 


\subsection{Robustness Check}

In this section, we perform a number of exercises to show the robustness of our baseline estimates to: (i) the use of an alternative distance measure to calculate market access, (ii) to the choice of the spatial weight matrix and (iii) potential endogeneity of market access. First, we re-estimate the baseline models using bird-eye distance in lieu of motorway distance. The results, displayed in Table 4, show that the direct and the total spatial effects in the conditional models are statistically distinguishable from zero at conventional test levels, albeit the magnitudes are lower than their counterparts in Table 3.

Next, we consider the possible influence of the spatial weight matrix in our empirical models and estimate all spatial models by using two alternative weight matrices: a contiguity-based and a k-nearest neighbor weight matrix $(k=4)$ in lieu of an inverse distance spatial weight matrix, whose results are given in Columns (1.X) and (2.X) of Table 5, respectively. The size of the spatial effects of market access are comparably similar to our baseline estimates with the exception of the SEM and the SDEM models where these effects are no longer statistically significant. Additionally, the direct spatial effects of market access under a SDM, relative to those reported in column (2.x) of Table 3 , are no longer statistically distinguishable from zero using either alternative spatial weight matrices. In general, our results are similar once results from these two new alternative weight matrices are compared. Even though there are minimal differences compared to the benchmark results, the spatial effects of market access are robust in general.

A potential threat to the identification of the models of section 3 rests with the possibility that MA may be endogenous to human capital accumulation. Table 6 reports the IV estimates of the NEG model using regional data as an accommodation for the possible endogeneity of market access. For the fact that the observations correspond to a collectively exhaustive set of provinces in Turkey, we perform a fixed-effects estimation in Table 6. A critical step to control for endogeneity is the instrument selection. One common approach is to use a distance-based geographical variable in order to construct a valid instrument (Boulhol and De Serres, 2010). While we follow this approach in our analyses, we additionally use the spatial lag of the market access as a spatial instrumental variable. Columns (1)-(3) use the first and the second order spatial lags of the natural logarithm of MA via a row-normalized first-order queen contiguity, a spectral inverse distance and a k-nearest neighbor spatial weight matrices, respectively. Next, following Boulhol and De Serres (2010) and Karahasan and López-Bazo (2013), the natural log of regional MA is instrumented by the sum of distance in column (5) and by the inverse sum of distance in column (6).

At the bottom of the Table 6, we report an exhaustive set of diagnostics on endogeneity, instrument relevance, weak identification and instrument validity. In order to test for instrument relevance and the endogeneity of market access, we report the heteroscedasticity consistent version of the Anderson canonical 
correlation LM statistic (Kleibergen-Paap LM statistic) and the endogeneity test. When the excluded instruments are only weakly correlated with the endogenous variable, the instrumental variable estimates will be biased in the same direction as the OLS and the significance tests will have incorrect size and confidence interval (Moreira, 2003). Therefore, we further report weak identification-robust inference test results.

The first-stage F-statistic, as a suggested measure to assess the explanatory power of the excluded instruments, reported at the bottom of the table, is well above 10 for all specifications, indicating that the instruments are not weak (Bound et al., 1995; Staiger and Stock, 1997). The strong correlation between market access and the instruments is further confirmed by the underidentification test results.

Having multiple instruments allows us to test for overidentifying restrictions through the Hansen J statistic. For the panel fixed-effects results shown in Table 6, we fail to reject the joint null hypothesis that the instruments are uncorrelated with the unobservable factors of human capital accumulation and that the excluded instruments are correctly excluded from the estimated equation only for columns (1) and (3) where MA is instrumented by the spatial lags of MA, using a contiguity-based and a k-nearest neighbor $(\mathrm{k}=4)$ spatial weight matrices, respectively. For the remaining models, Hansen J statistic suggests that the overidentifying restrictions are not met. Yet, the weak identification-robust inference (conditional LR) test results indicate that the null hypothesis that the coefficient on MA is zero can be rejected for all specifications at conventional test levels.

The IV diagnostics yield conflicting results with respect to both the endogeneity of MA as well as to the validity of the instruments. Two thirds of the panel fixed-effects IV results are inadmissible for the fact that the overidentifying restrictions are not met (columns (2), (4)-(6)); yet MA appears to be exogenous in these models. In the remaining models, there is a clear evidence that MA is endogenous and the overidentifying restrictions are also met. Despite the equivocal evidence based on the fixed-effects IV estimates, the magnitude of the estimate of the effect of MA along with its standard errors are very similar across all six specifications, that MA drives up human capital accumulation by about 1 percent (i.e. unitelastic). Overall, the relationship between MA and human capital accumulation is robust to alternative market access measurement, spatial weight matrix specification and to the possible endogeneity of MA.

\section{Discussion}

Development and growth economics explore the dynamics and sources of cross-country differences. Evidence suggests that socio-economic characteristics of countries and their development paths are endogenously related. As economic and social inequalities are not limited to cross-country comparisons, scholarly interest shifts towards intra-country differences. Rapid surge in the developmental aspects of regional studies becomes 
even more aspiring as more work has been conducted to understand the reasons behind the evolution of regional differences in the sources of economic development. Recent advances in the NEG give a momentum to scholars to explore the different dimensions of regional development. However, most studies test the link between geography and inequalities, by and large measured by income and productivity differences. In our analyses, we focus on the relationship between market access and human capital disparities rather than comparing geography with overall inequalities. To our knowledge, this is one of the first few attempts for a developing country suffering from persistent spatial instabilities. Therefore, an important expected contribution of this study, is the attention paid to the inevitable links between development aspects of regional disparities and its empirical examination by the recent setup of the NEG theory. This process as an inevitable and valuable line of future research for development studies.

Our analyses suggest highly persistent spatial spillovers and massive rigidities in the local realization of spatial relationships between market access and human capital differences in Turkey. Importantly, regions located in clusters of high (low) human capital accumulation have high (low) market accessibility. Overall, this process creates a rapidly evolving dichotomy both for market accessibility and human capital disparities, suggesting that investigating the causal channels through the NEG framework is essential.

The spatial evolution of market access and human capital differences is followed by an empirical estimation of the NEG model. We construct a setup that enables us to directly test the NEG model (Redding and Schott, 2003). However, unlike the original model, we use different spatial specifications together with a detailed discussion on the possible endogeneity of MA. Incorporating spatial mechanisms to the market access and human capital link is an important dimension for understanding regional disparities in developing countries. Using spatial batteries in the specification does not only act as a robustness check but also stands as an important tool in order to understand the spatial borders of the relations that are essential for policy making. For instance, it is possible to question the influence market access on human capital in a region by also taking into account the human capital and market access level of the surrounding regions. Likewise, unobserved common chractersitics of regions in spatial links can be significant, reminding the possible homogeneity of policy influences over various policy tools linked with unobserved local properties (i.e. cultural, ethnic, conflict-driven etc.). Especially when the non-market oriented public policy tools are considered to enhance human capital in a region, spatial networks point out to the possibility of the influences of policies beyond the borders of regions. This could not be controlled for within the original model. Moreover, we consider various dimensions of regional differences and use additional controls as determinants of human capital differences. We argue that structural regional disparities are important elements in understanding the evolution of regional human capital gaps. We also consider a number of technical issues such as market access calculation (i.e. motorway and bird-eye distances) and spatial weight matrix construction (i.e. inverse distance, k- 
nearest neighbor and contiguity weight matrices). Our empirical results confirm the NEG's expectations. Market access is an important dimension of human capital accumulation and the NEG model works well in a developing country example even after other methodological issues such as; measurement of market access and different weight matrix specifications are accounted for. We also consider the possible endogeneity of market access as some unobserved regional characteristics (i.e. skill level of the work forces, attractiveness of the regions) may be in effect or a reverse causation may bias our inferences. Therefore, we use a number of instrumental variables to account for this endogeneity and point out to the overall robustness of our results.

Our results also show interesting similarities and differences with previous studies. While our results are in line with the previous evidence from a set of EU regions (Faíña and López-Rodríguez, 2006; LópezRodríguez et al., 2007; Diebolt and Hippe, 2018) and for some country cases (i.e. Romania (López-Rodríguez et al., 2019)), they depict a somewhat different story than those of Karahasan and López-Bazo (2013) who established a diminished impact of market access with the inclusion of several other dimensions for Spanish regions. A comparison of the similarities of an entire region (i.e. EU) with a single country could be challenging; however, a contrast between two countries may yield valuable information on the true nature of the NEG for policy-making. We argue that the administrative structural differences are an important dimension, particularly in countries of extremely centralized policy-making such as Turkey. On the contrary, regional autonomy in Spain is permissive to local policies. Given that market access is extremely rigid (i.e. policy-insensitive), the loss of the impact of market access in Spain can be attributed to the extent of local policies. Centralized policy-making in Turkey may decrease the effectiveness of social policies and to some extent, may explain the reason behind the robust and the strong impact of market accessibility.

Our evidence supports the view that geography and remoteness can play a dominant role in developing countries. This broaches the question of how a developing country can cope with this remoteness problem given that market access is policy-insensitive. Evidence from developed countries with different levels of local autonomy has much to offer on the extent and success of local policies that diminish the impact of market accessibility, which is found to be policy-insensitive. Therefore, surmounting the inertia of the impact of market access may only work in developing countries if they pursue policies that consider local necessities.

A limitation of our study is that it does not cover the background of the NEG model whose central expectation relies on the assumption that wages is the true incentive to increase investment in human capital accumulation. That is, market access directly influences wage dispersion, which in turn affects education investment. Relatedly, there is an intertemporal dimension as individuals' investment decision in education, returns to education and actual education attainment occur in different periods. Additionally, the reason behind the detection of highly educated individuals in central location may stem from the fact that skill distribution and demand is higher in already developed central regions. It is possible that denser central 
areas (i.e. city centers) may be attracting more people not only because these areas have higher market potential, but also skill and ability demand is biased in these core attractive centers (Crozet, 2004; Combes et al., 2008; Mion and Naticchioni, 2009; Combes et al., 2010). A potential solution would be to use wage and occupation data to control for the endogenous feedback among human capital accumulation, returns to education and market accessbility. First, lack of aggregate data on wages at the NUTS III level does not allow us to assess the structural relationship between human capital accumulation and returns of education (i.e. wages) but only the reduced relationship between the former and market access. Second, it is not possible to foresee the impact of the attractiveness of central regions with high market accessibility because we are unable to control for a detailed employment and occupation composition at regional level. Despite these limitations, our findings enable us to identify the extent of inertia between geographical proximity and educational human capital disparities. Economic policies to combat this dilemma are most effective only if these three dimensions are considered in a coherent manner. Using different data sets (i.e. micro level at more aggregate level) in order to combine these three dimensions is the future line of research on our agenda.

\section{Conclusion}

The central objective of this research is to question the impact of market access on human capital development for the regions of Turkey. Originating from the NEG's formulation, we argue that regions with higher market access accumulate more human capital. Furthermore, such a link should be tested for issues such as spatial externalities, regional heterogeneities, some other regional socio-economic factors and possible endogeneity of market accessibility.

Our results confirm that market access significantly influences regional human capital development in Turkey. These results are robust to the inclusion of sectoral controls, regional heterogeneities, spatial spillovers and the endogeneity of market access. Overall, findings point out that regional policies fail to solve the ongoing and persistent human capital gaps problem in Turkey. Moreover, given the inertia in market access and the robust link between market access and human capital accumulation, there is evidence for the ineffectiveness of the current social policies to combat disparities. This however does not directly imply that there is lack of room for policy-making, rather this signals out the failure of the current set of regional policies that are highly centralized and are implemented without enough concern on local heterogeneities.

The, results of the study should open up new discussions for the strength of the proposed channels between market accessibility and human capital accumulation. The positive influence of market access on human capital accumulation could be attributed to some unobserved regional factors. Wage distribution and attractiveness of dense urban areas could also be responsible for the clustering of highly educated 
individuals in central locations. This does not necessarily imply that market access is ineffective but rather signals the need for more in-depth analyses of the mechanisms within the NEG model. These relations could be working together with the influence of market access or some other unknown mechanisms could be mediating the overall relation between market accessibility and accumulation of human capital. Investigating these challenging lines with the availability of individual-level micro data is an important and valuable line of future research for scholars. 


\section{References}

Alvarado, M.l, R.and Atienza et al. (2014): The role of market access and human capital in regional wage disparities: Empirical evidence for Ecuador. Tech. rep., Universidad Católica del Norte, Chile, Department of Economics.

Amaral, P.V.; M. Lemos; R. Simões; and F. Chein (2010): Regional imbalances and market potential in Brazil. Spatial Economic Analysis, 5(4):463-482.

Anderson, J.E. and E. Van Wincoop (2004): Trade costs. Journal of Economic Literature, 42(3):691-751.

Anselin, L. (1995): Local indicators of spatial association-LISA. Geographical Analysis, 27(2):93-115.

Anselin, L. (1996): The Moran scatterplot as an ESDA tool to assess local instability in spatial association. Spatial analytical perspectives on GIS, 111:111-125.

Anselin, L. (2010): Thirty years of spatial econometrics. Papers in Regional Science, 89(1):3-25.

Barro, R.J. and X. Sala-i Martin (1995): Economic Growth. MIT Press.

Becker, G.S. (1964): Human capital: A theoretical and empirical analysis, with special reference to education. University of Chicago press.

Benhabib, J. and M.M Spiegel (1994): The role of human capital in economic development evidence from aggregate cross-country data. Journal of Monetary economics, 34(2):143-173.

Bosker, M. and H. Garretsen (2010): Trade costs in empirical new economic geography. Papers in Regional Science, 89(3):485-511.

Boulhol, H. and A. De Serres (2010): Have developed countries escaped the curse of distance? Journal of Economic Geography, 10(1):113-139.

Bound, J.; D.A. Jaeger; and R.M. Baker (1995): Problems with instrumental variables estimation when the correlation between the instruments and the endogenous explanatory variable is weak. Journal of the American Statistical Association, 90(430):443-450.

Brakman, S.; H. Garretsen; and M. Schramm (2006): Putting new economic geography to the test: Free-ness of trade and agglomeration in the EU regions. Regional Science and Urban Economics, 36(5):613-635.

Breinlich, H. (2006): The spatial income structure in the European Union what role for Economic Geography? Journal of Economic Geography, 6(5):593-617. 
Burridge, P. (1981): Testing for a common factor in a spatial autoregression model. Environment and Planning A, 13(7):795-800.

Cizre, Ü. and E. Yeldan (2005): The Turkish encounter with neo-liberalism: economics and politics in the 2000/2001 crises. Review of International Political Economy, 12(3):387-408.

Coe, D.T. and E. Helpman (1995): International r\&d spillovers. European Economic Review, 39(5):859-887.

Coe, D.T.; E. Helpman; and A. Hoffmaister (1995): North-south RED spillovers. Tech. rep., National Bureau of Economic Research.

Combes, P.; G. Duranton; and L. Gobillon (2008): Spatial wage disparities: Sorting matters! Journal of urban economics, 63(2):723-742.

Combes, P.; G. Duranton; L. Gobillon; and S. Roux (2010): Estimating agglomeration economies with history, geology, and worker effects. In: Agglomeration economics, University of Chicago Press, pp. 15-66.

Crozet, M. (2004): Do migrants follow market potentials? An estimation of a new economic geography model. Journal of Economic Geography, 4:439-458.

Diebolt, C. and R. Hippe (2018): Remoteness equals backwardness? Human capital and market access in the European regions: insights from the long run. Education Economics, 26(3):285-304.

Doğruel, F. (2006): Türkiye'de Bölgesel Politikalar. Değişen Türkiye Dönüşen Mekan, Ed. A. Eraydın, pp. 164-195.

Doğruel, F. and S. Doğruel (2003): Iktisat Üzerine Yazılar I Küresel Düzen: Birikim, Devlet ve Sınıflar Korkut Boratav'a Armağan, Iletişim Publications, chap. Türkiye'de Bölgesel Gelir Farklılıkları ve Büyüme.

Elhorst, J.P. (2010): Applied spatial econometrics: raising the bar. Spatial Economic Analysis, 5(1):9-28.

Erdem, U. (2016): Regional human capital distribution and disparities in Turkey. Review of Urban $\mathcal{E}^{3}$ Regional Development Studies, 28(1):16-31.

Faína, J A. and J. López-Rodríguez (2006): Market access and human capital accumulation: the European Union case. Applied Economics Letters, 13(9):563-567.

Filiztekin, A. (1998): Convergence across industries and provinces in Turkey. Koc University, http://myweb. sabanciuniv. edu/alpayf/files/2010/04/turkconv981. pdf. 
Filiztekin, A. and B.C. Karahasan (2015): Mapping the Educational Attainment in Turkey. In: Proceedings of Ekonomik Yaklaşımlar International Congress of Economics II-Growth, Inequality and Poverty. No. 285.

Fingleton, B. (2008): Competing models of global dynamics: evidence from panel models with spatially correlated error components. Economic Modelling, 25(3):542-558.

Fujita, M.; P.R. Krugman; and A.J. Venables (1999): The spatial economy: cities, regions and international trade. MIT Press.

Gallup, J.L.; J.D. Sachs; and A.D. Mellinger (1999): Geography and economic development. International Regional Science Review, 22(2):179-232.

Gezici, F. and G.J.D. Hewings (2007): Spatial analysis of regional inequalities in Turkey. European Planning Studies, 15(3):383-403.

Hanson, G.H. (2005): Market potential, increasing returns and geographic concentration. Journal of International Economics, 67(1):1-24.

Harris, C.D. (1954): The, Market as a Factor in the Localization of Industry in the United States. Annals of the association of American geographers, 44(4):315-348.

Head, K. and T. Mayer (2006): Regional wage and employment responses to market potential in the EU. Regional Science and Urban Economics, 36(5):573-594.

Head, K. and T. Mayer (2011): Gravity, market potential and economic development. Journal of Economic Geography, 11(2):281-294.

Henderson, J.V.; Z. Shalizi; and A.J. Venables (2001): Geography and Development. Journal of Economic Geography, 1:81-105.

Hering, L. and S. Poncet (2010): Market access and individual wages: Evidence from China. The Review of Economics and Statistics, 92(1):145-159.

Howitt, P. (2000): Endogenous growth and cross-country income differences. American Economic Review, 90(4):829-846.

Karahasan, B.C.; F. Dogruel; and S. Dogruel (2016): Can Market Potential Explain Regional Disparities in Developing Countries? Evidence from Turkey. The Developing Economies, 54(2):162-197. 
Karahasan, B.C. and E. López-Bazo (2013): The spatial distribution of human capital: can it really be explained by regional differences in market access? International Regional Science Review, 36(4):451-480.

Keller, W. (January 2000): Geographic Localization of International Technology Diffusion. Working Paper 7509, National Bureau of Economic Research.

Kosfeld, R. and H. Eckey (2010): Market access, regional price level and wage disparities: the German case. Jahrbuch für Regionalwissenschaft, 30(2):105-128.

Krugman, P. (1991): Increasing returns and economic geography. Journal of Political Economy, 99(3):483499.

Krugman, P. and A.J. Venables (1995): Globalization and the Inequality of Nations. The Quarterly Journal of Economics, 110(4):857-880.

Lagendijk, A.; S. Kayasu; and S. Yasar (2009): The role of regional development agencies in Turkey: From implementing EU directives to supporting regional business communities? European Urban and Regional Studies, 16(4):383-396.

LeSage, J.P. and R.K. Pace (2009): Introduction to Spatial Econometrics (Statistics, textbooks and monographs). CRC Press.

López-Rodríguez, J. (2015): Regional Income Disparities in Poland: Analysis of the Impact of Second Nature Geography Varibles. Transformations in Business 83 Economics, 14(3).

López-Rodríguez, J.; C. Bolea; and P. Montes-Solla (2019): Sorting Skills by Location in Romania. European Research Studies, 22(2):3-27.

López-Rodríguez, J.; J.A. Faíña; and J. López-Rodríguez (2007): Human capital accumulation and geography: empirical evidence from the European Union. Regional Studies, 41(2):217-234.

López-Rodríguez, Jesús; A. Faina; and C. Bolea (2011): Economic remoteness and wage disparities in Romania. Tijdschrift voor economische en sociale geografie, 102(5):594-606.

López-Rodríguez, Jesús; M. Runiewicz-Wardyn; et al. (2014): Changing market potentials, regional growth and income disparities in Poland. Prague Economic Papers, 1:63-83.

Lucas, R. (1988): On the mechanisms of development planning. Journal of Monetary Economics, 22(1):3-42.

Mion, G. (2004): Spatial externalities and empirical analysis: the case of Italy. Journal of Urban Economics, $56(1): 97-118$. 
Mion, G. and P. Naticchioni (2009): The spatial sorting and matching of skills and firms. Canadian Journal of Economics/Revue canadienne d'économique, 42(1):28-55.

Monastiriotis, V. (2009): Examining the consistency of spatial association patterns across socio-economic indicators: an application to the Greek regions. Empirical Economics, 37(1):25-49.

Moreira, M.J. (2003): A conditional likelihood ratio test for structural models. Econometrica, 71(4):10271048.

Motellón, E.; E. López-Bazo; and M. El-Attar (2011): Regional heterogeneity in wage distributions: evidence from Spain. Journal of Regional Science, 51(3):558-584.

Niebuhr, A. (2006): Market access and regional disparities. The Annals of Regional Science, 40(2):313-334.

Ottaviano, G.I.P. and D. Pinelli (2006): Market potential and productivity: evidence from Finnish regions. Regional Science and Urban Economics, 36(5):636-657.

Psacharopoulos, G. (1988): Education and development: a review. The World Bank Research Observer, $3(1): 99-116$.

Redding, S. and P.K. Schott (2003): Distance, skill deepening and development: will peripheral countries ever get rich? Journal of Development Economics, 72(2):515-541.

Redding, S. and A. Venables (2004a): Geography and export performance: external market access and internal supply capacity. In: Challenges to globalization: Analyzing the economics, University of Chicago Press, pp. 95-130.

Redding, S. and A.J. Venables (2004b): Economic geography and international inequality. Journal of international Economics, 62(1):53-82.

Redding, S.J. (2010): The empirics of new economic geography. Journal of Regional Science, 50(1):297-311.

Romer, P.M. (1994): The origins of endogenous growth. The Journal of Economic Perspectives, 8(1):3-22.

Sala-i Martin, X. (1994): Cross-sectional regressions and the empirics of economic growth. European Economic Review, 38(3-4):739-747.

Solow, R.M. (1956): A contribution to the theory of economic growth. The Quarterly Journal of Economics, 70(1):65-94.

Staiger, D. and J.H. Stock (1997): Instrumental Variables Regression with Weak Instruments. Econometrica, 65(3):557-586. 
Stock, J.H. and M. Yogo (2005): Testing for Weak Instruments in Linear IV Regression. in: Identification and Inference for Econometric Models: Essays in Honor of Thomas Rothenberg.

Turkstat (2019): Turkish Statistics Office Regional Database. https://biruni.tuik.gov.tr/bolgeselistatistik/anaSayfa.do?dil=en.

Venables, A.J. (1996): Equilibrium locations of vertically linked industries. International Economic Review, 37(2):341-359. 


\section{A Tables}

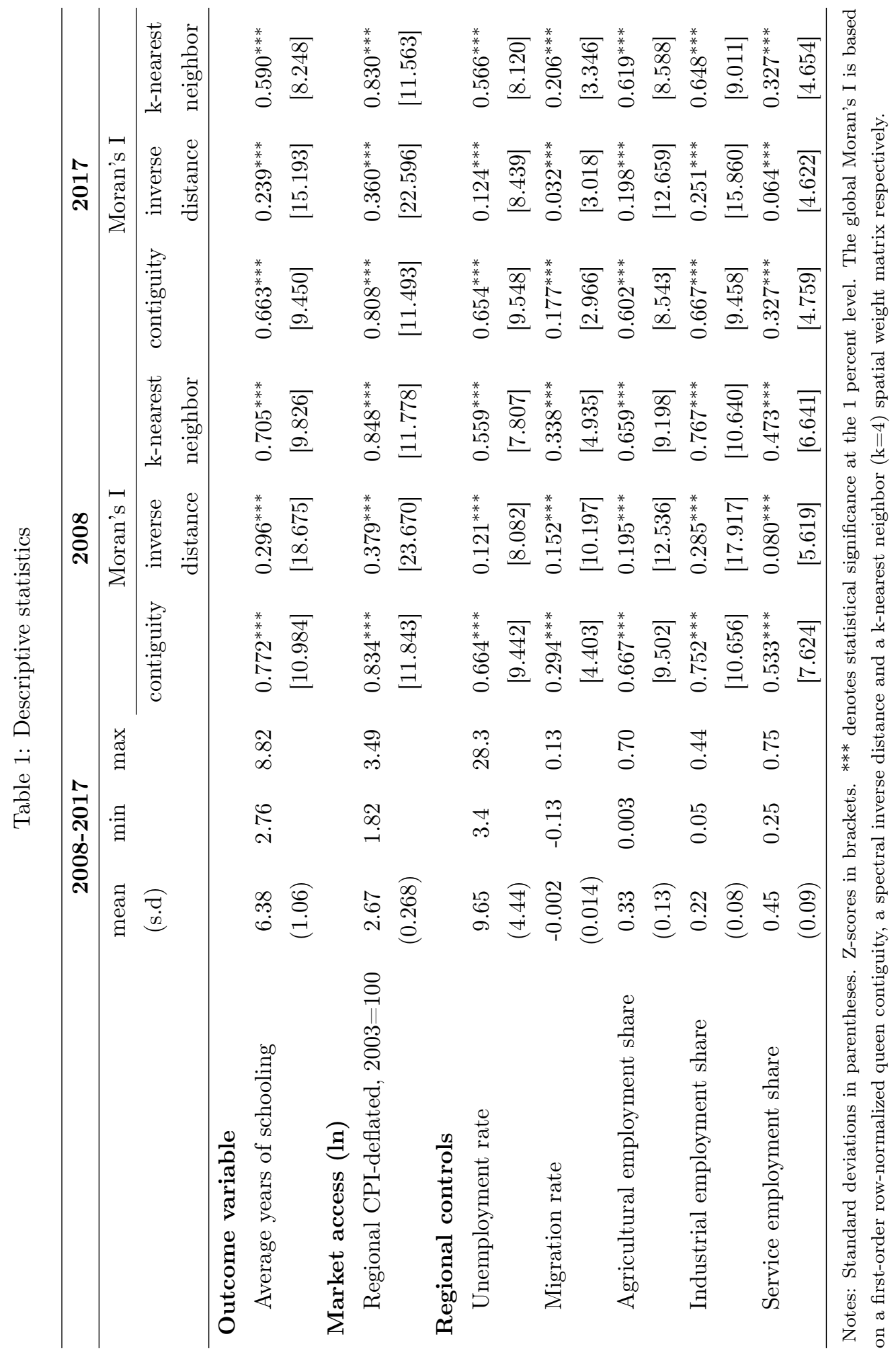


Table 2: Decomposition of Spatial Auto-correlation

\begin{tabular}{ccccccccc}
\hline & \multicolumn{3}{c}{ Market access } & \multicolumn{4}{c}{ Average years of schooling } \\
\cline { 2 - 9 } & High-High & Low-Low & High-Low & Low-High & High-High & Low-Low & High-Low & Low-High \\
\hline 2008 & 0.43 & 0.40 & 0.02 & 0.15 & 0.48 & 0.31 & 0.12 & 0.09 \\
2009 & 0.47 & 0.40 & 0.02 & 0.11 & 0.46 & 0.28 & 0.16 & 0.10 \\
2010 & 0.46 & 0.40 & 0.02 & 0.12 & 0.46 & 0.27 & 0.17 & 0.10 \\
2011 & 0.44 & 0.41 & 0.01 & 0.14 & 0.44 & 0.30 & 0.17 & 0.09 \\
2012 & 0.44 & 0.41 & 0.01 & 0.14 & 0.46 & 0.31 & 0.15 & 0.09 \\
2013 & 0.44 & 0.40 & 0.02 & 0.14 & 0.46 & 0.31 & 0.15 & 0.09 \\
2014 & 0.44 & 0.41 & 0.01 & 0.14 & 0.41 & 0.30 & 0.19 & 0.11 \\
2015 & 0.43 & 0.37 & 0.05 & 0.15 & 0.41 & 0.31 & 0.17 & 0.11 \\
2016 & 0.43 & 0.40 & 0.02 & 0.15 & 0.41 & 0.31 & 0.17 & 0.11 \\
2017 & 0.43 & 0.40 & 0.02 & 0.15 & 0.41 & 0.31 & 0.17 & 0.11 \\
\hline
\end{tabular}

Notes: Figures show the percentage of provinces that fall within each spatial cluster for a given year. 


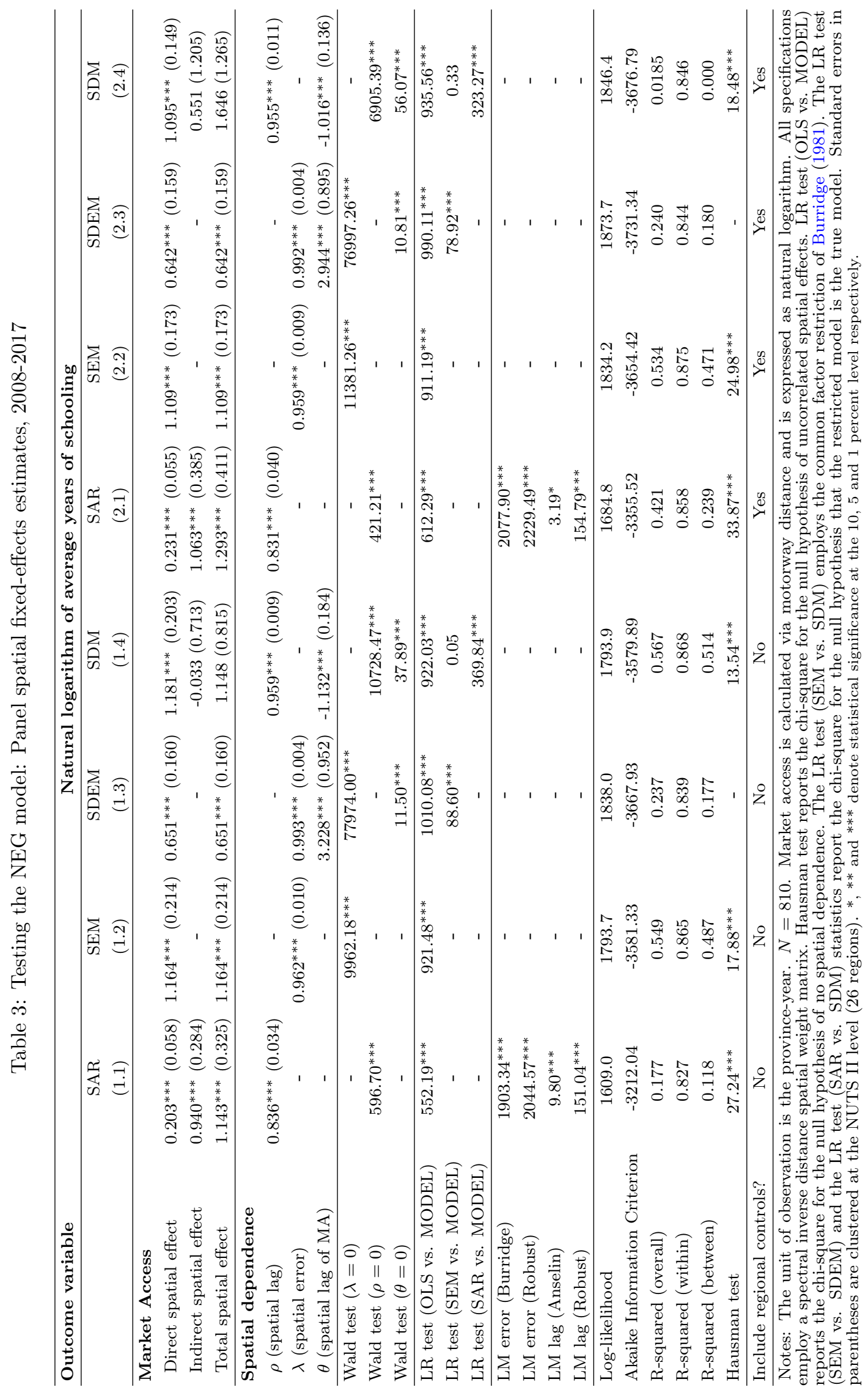




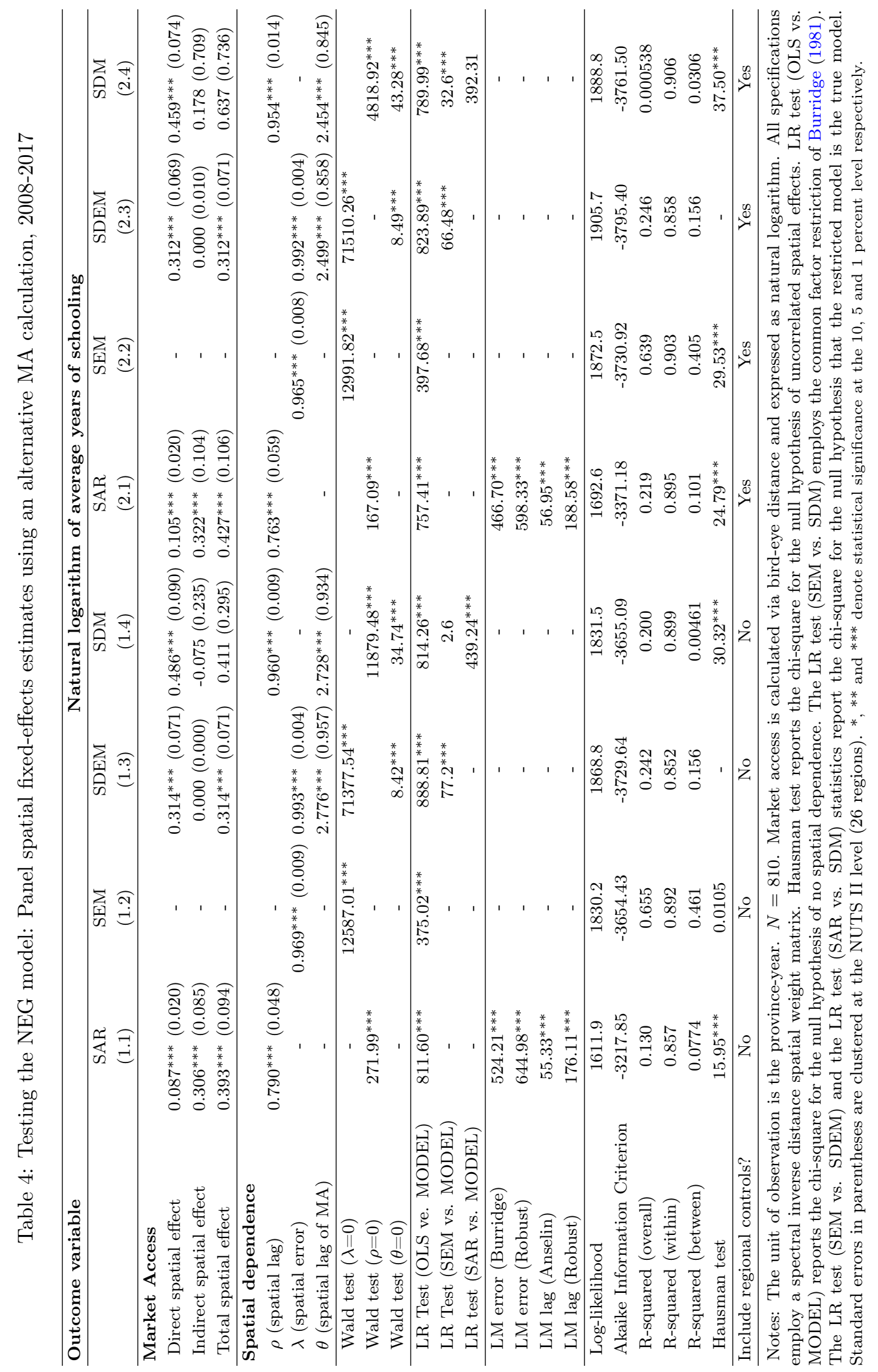




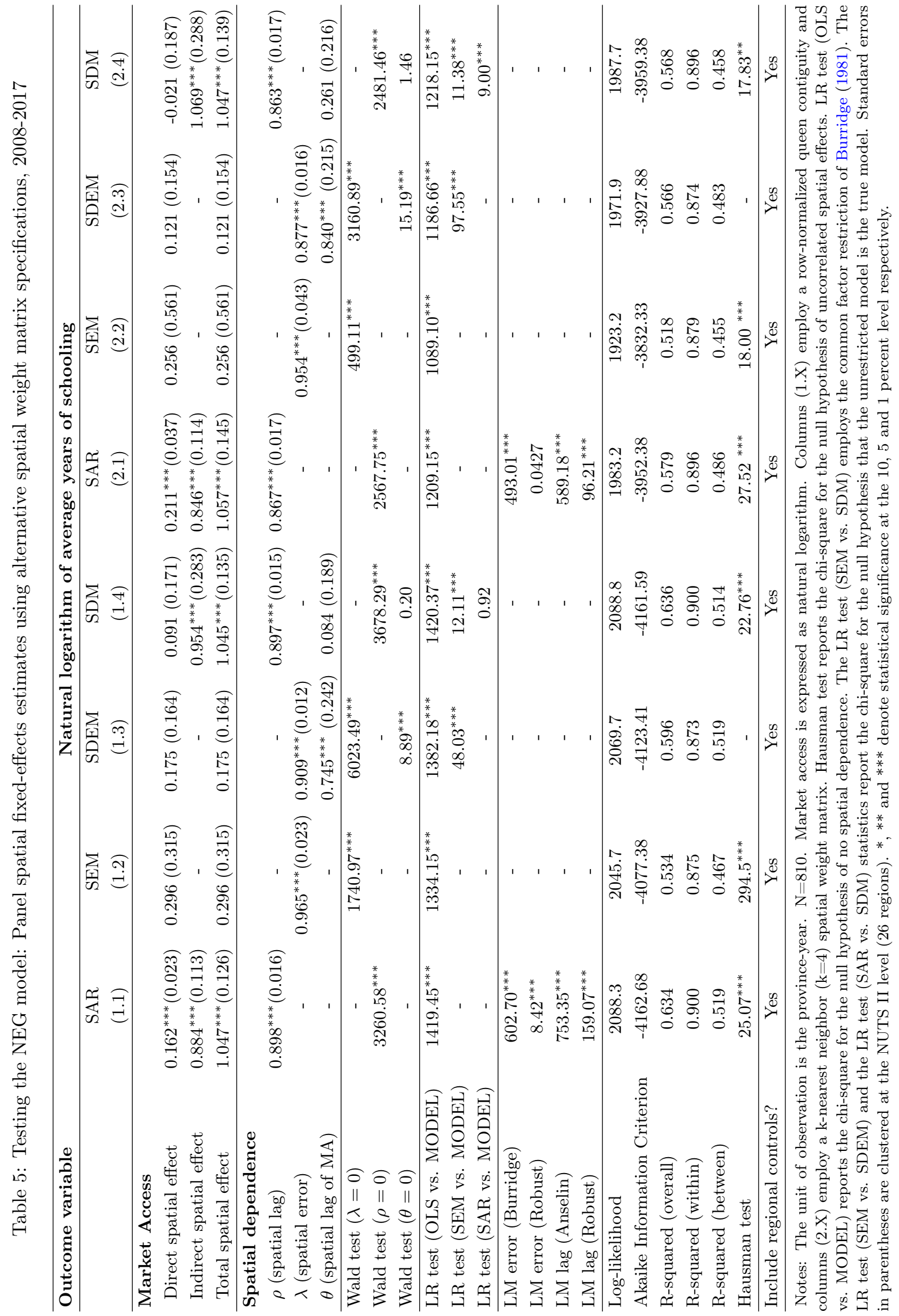




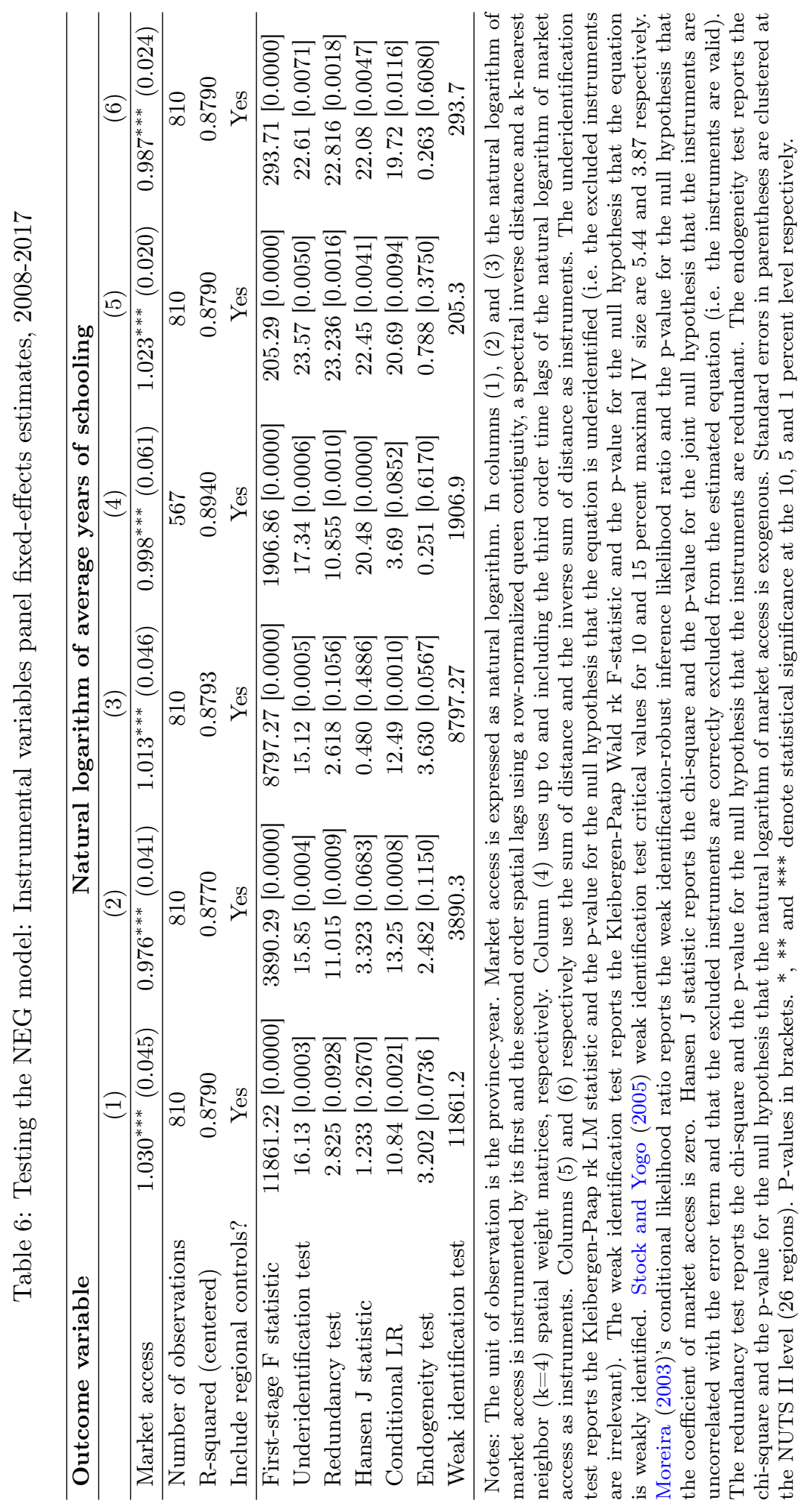




\section{B Figures}

Figure 1: Average Years of Schooling

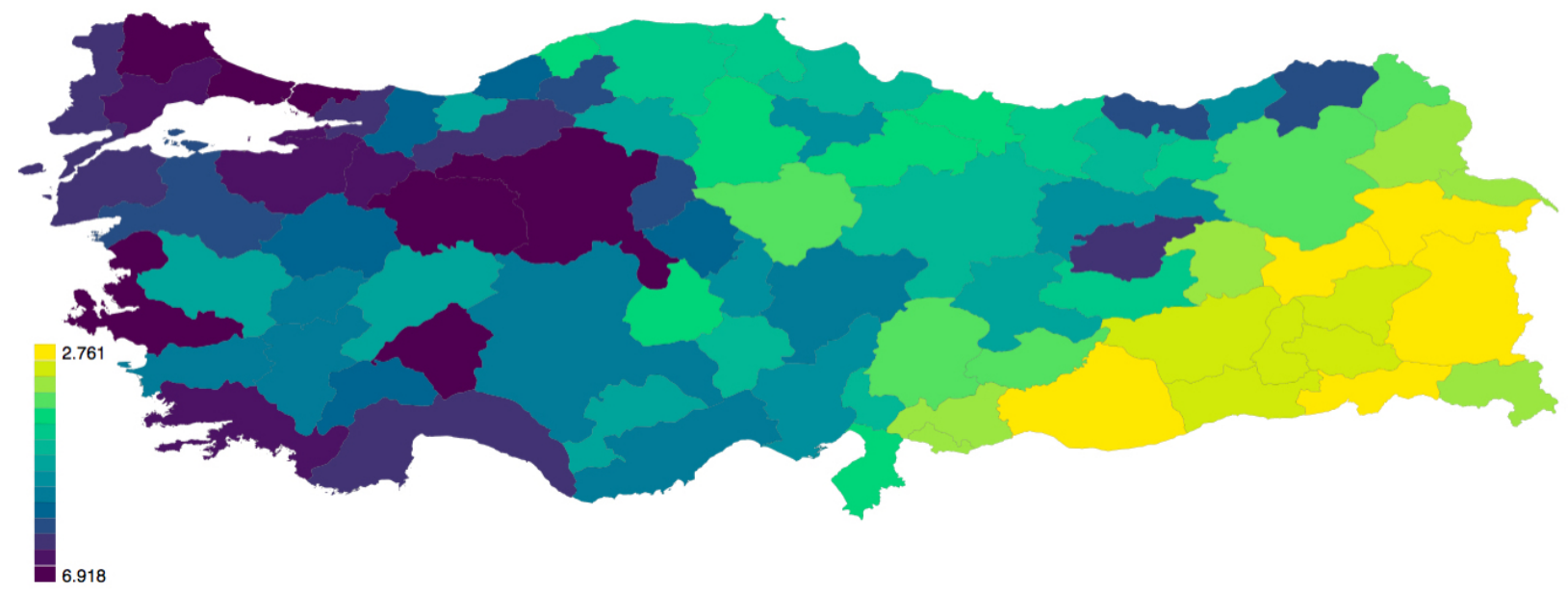

(a) 2008

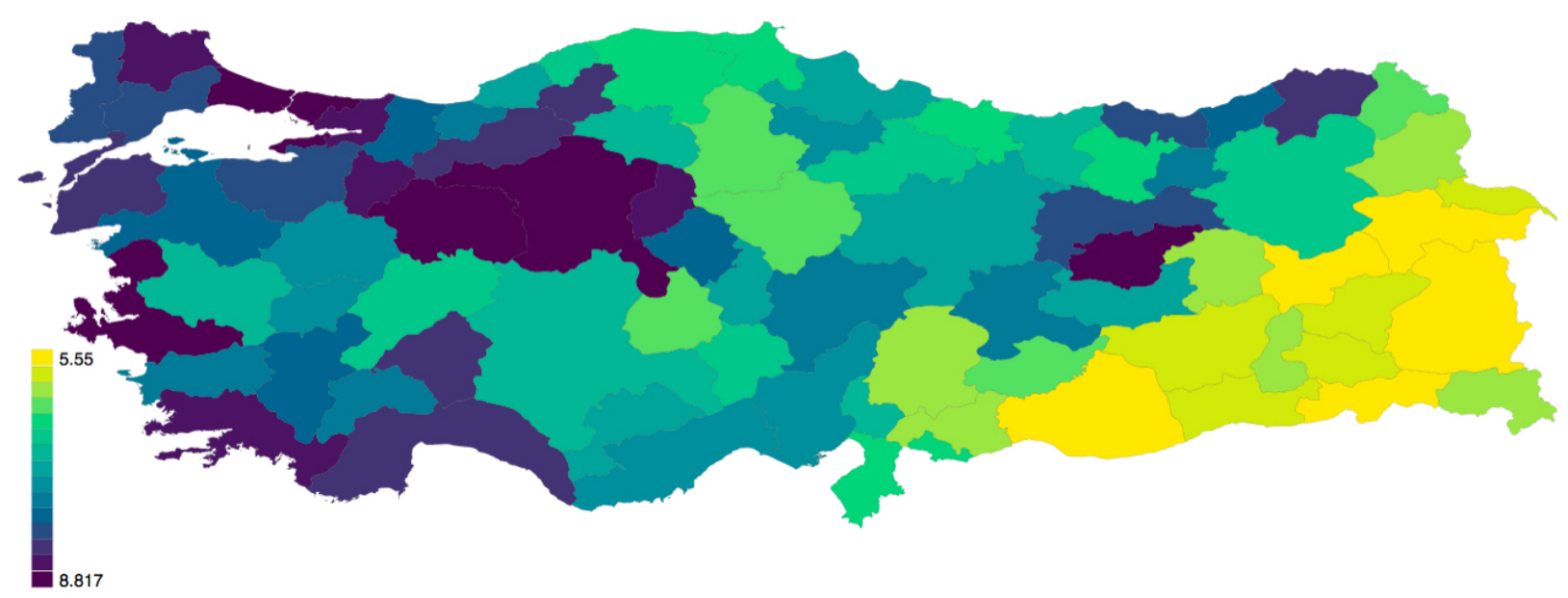

(b) 2017

Source:Turkstat (2019), Authors' own calculations 
Figure 2: Regional CPI-deflated market access, 2003=100 (in natural logs)

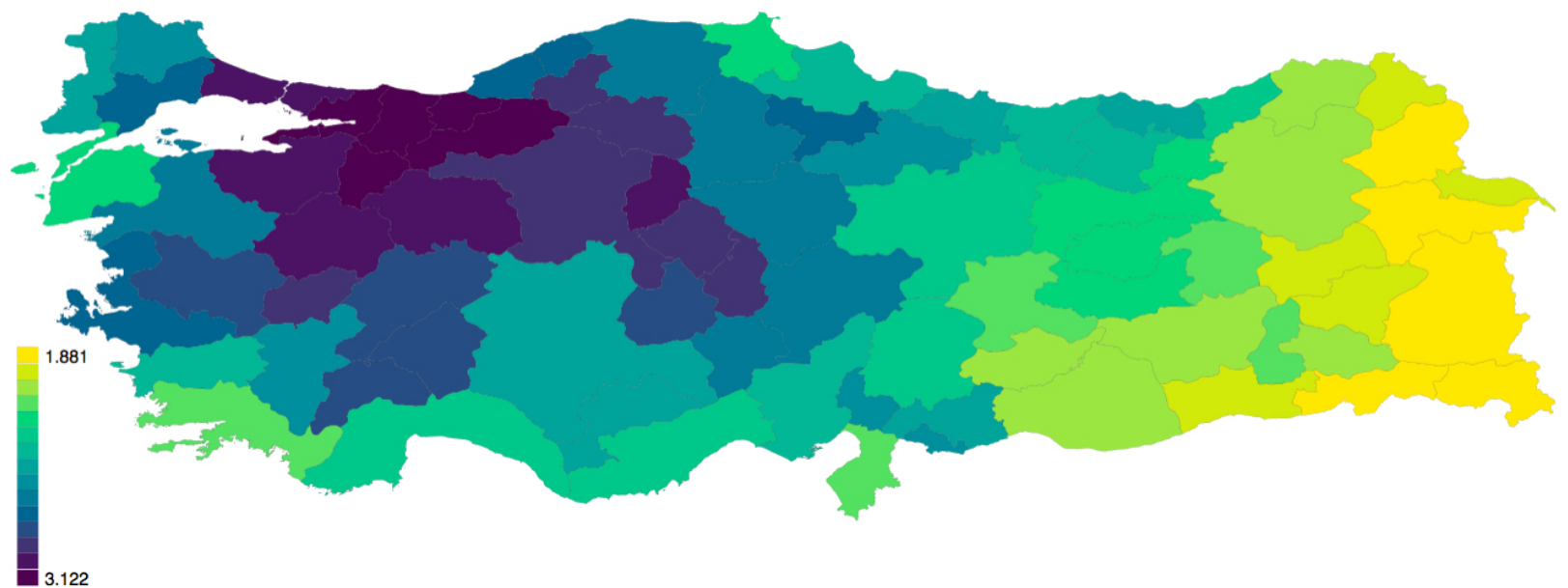

(a) 2008

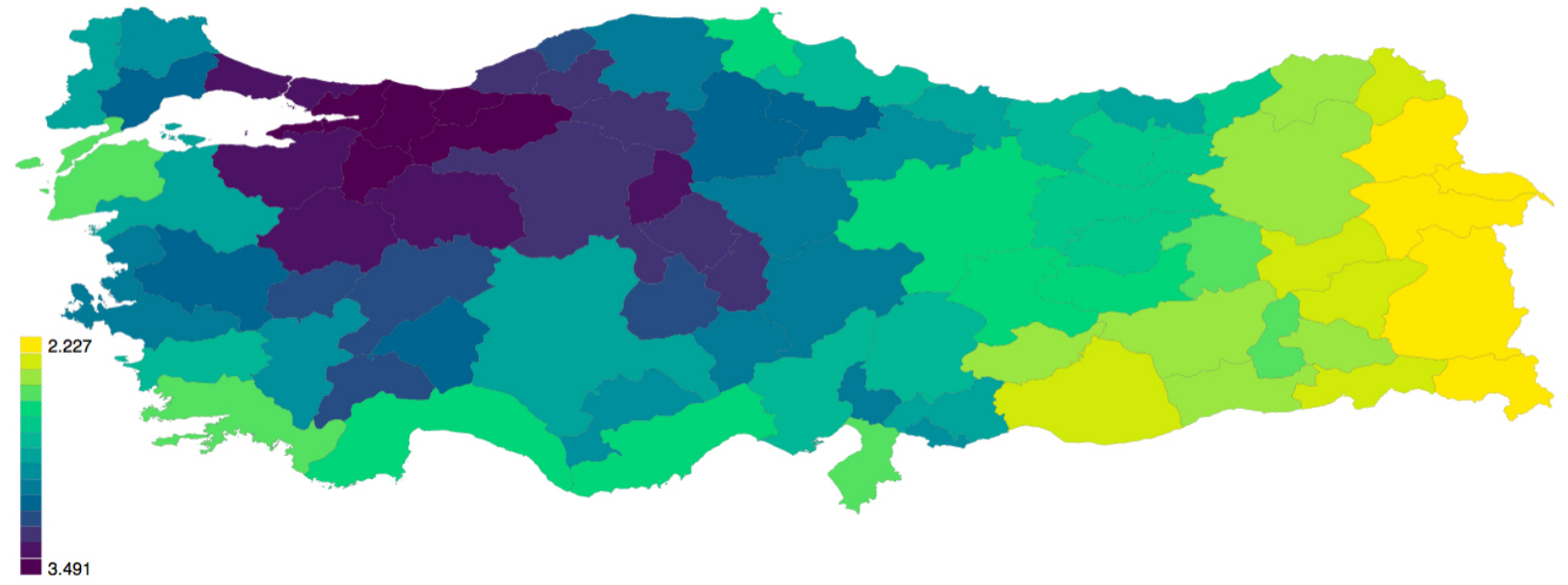

(b) 2017

Source:Turkstat (2019), Authors' own calculations 
Figure 3: Relationship between Human Capital Development and Distance-2008
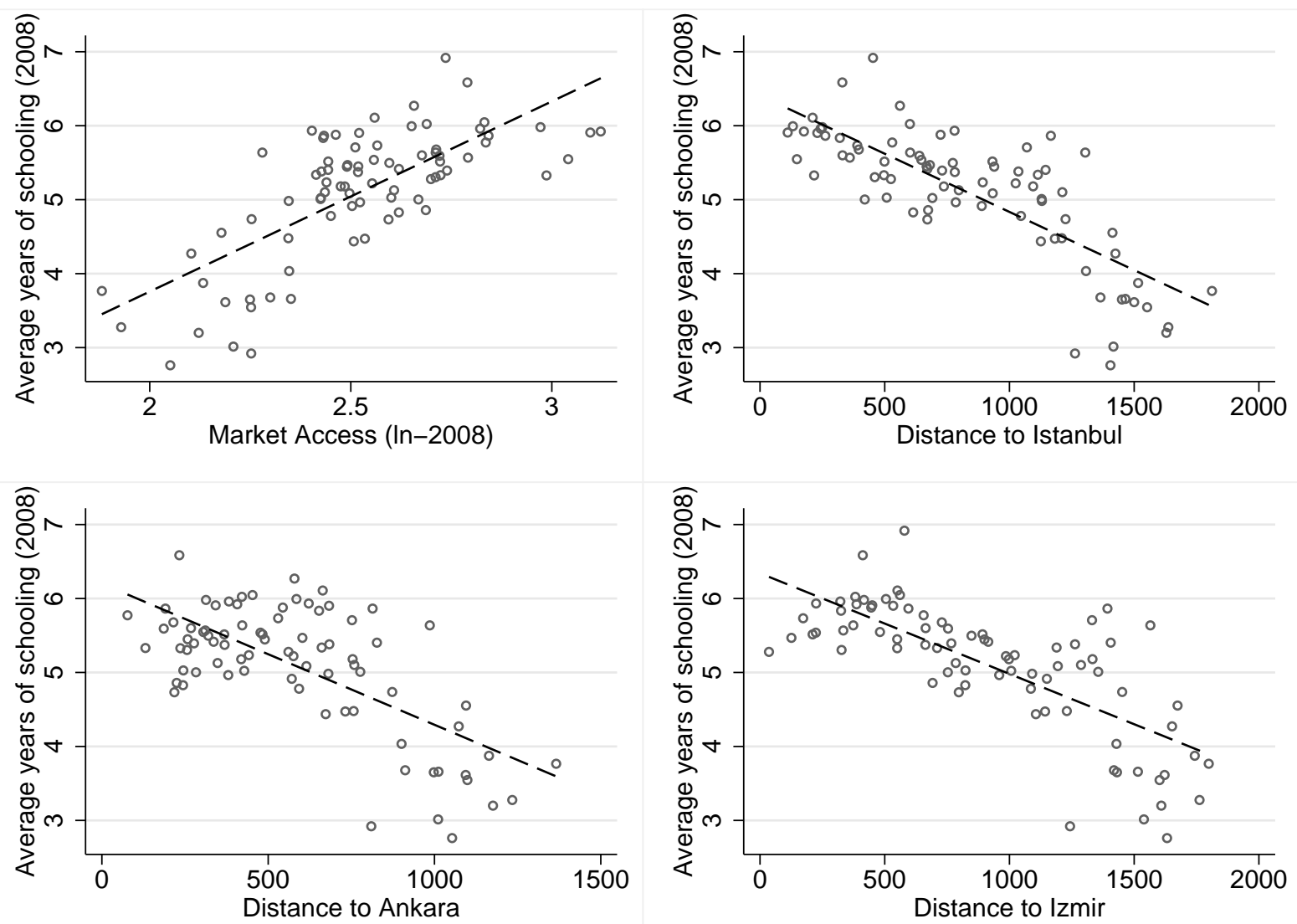

Source:Turkstat (2019), Authors' own calculations 
Figure 4: Relationship between Human Capital Development and Distance-2017
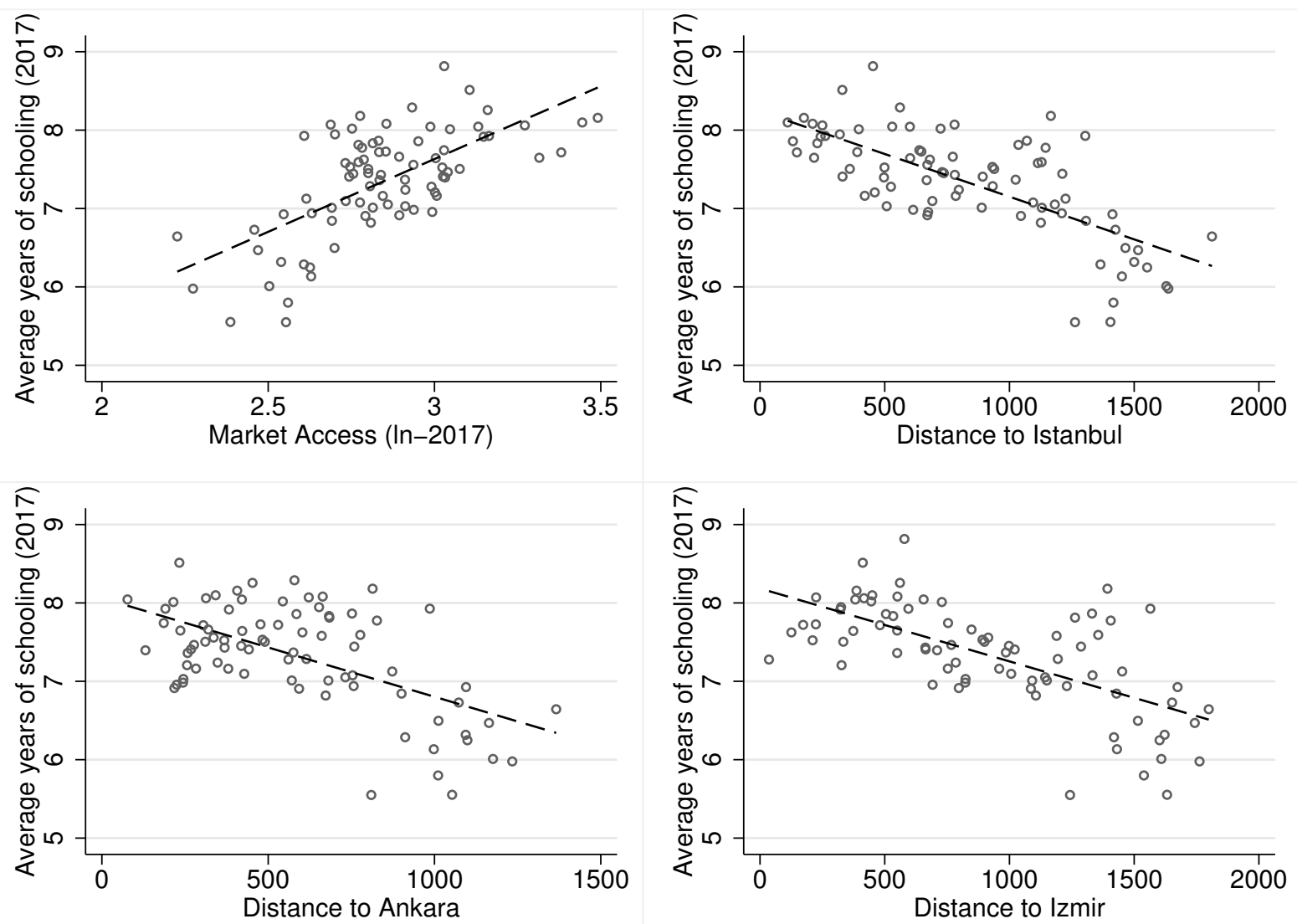

Source:Turkstat (2019), Authors' own calculations 